\title{
An empirical study of portfolio management and Kanban in agile and lean software companies
}

\author{
Muhammad Ovais Ahmad, Lucy Ellen Lwakatare, Pasi Kuvaja, Markku Oivo, Jouni Markkula \\ M3S Research Unit, Faculty of Information Technology and Electrical Engineering, University of Oulu, Finland
}

FIRST NAME.LAST NAME @OULU.FI

\begin{abstract}
Traditional portfolio management tools and methods are challenging for software companies that use agile and lean approaches, due to the complex pre-planning activities required. In this paper, traditional portfolio management tools and methods that have been conventionally used in industry and presented in literature are reviewed. Findings concerning their use in agile and lean software companies are investigated, based on the literature review and semi-structured interviews conducted in seven agile and lean software companies in Finland. The findings indicate that the studied companies do not use traditional portfolio management tools and methods in their entirety. The software companies adapted suitable components from traditional portfolio management tools and methods into their practices. They also apply new tools and methods to manage their portfolios of offerings, in order to cope with the dynamics required by agile and lean methods. The companies' emphasis is on using tools to facilitate immediate feedback from customers, in order to assess the value of offerings in their portfolio. The results showed a growing interest in using Kanban at the portfolio level to provide a visual overview of offerings.
\end{abstract}

KEY WORDS: portfolio; lean; agile; Kanban; software product management

\section{INTRODUCTION}

Portfolio management has been in existence for several decades since its origins from portfolio theory in finance in the 1950s [1]. Companies use portfolio management to ensure effective use of limited resources and to achieve balance of resources in terms of value maximization, strategic alignment, risk level and number of ongoing products and projects. According to Cooper, Edgett and Kleinschmidt [2], portfolio management 'is a dynamic decision making process whereby a business's list of active new products and R\&D projects is constantly up-dated and revised'. The process involves the evaluation, selection and prioritization of new projects at the same time as existing projects are re-evaluated for resources allocation and reallocation to active projects. In the context of this study, portfolio management looks at a combination of new and existing products and services that are collectively grouped to ensure their effective management which is aligned with strategic business objectives crucial for creating value.

Today, a growing number of software companies have adopted agile and lean approaches [7] in order to successful in global markets, software companies must incorporate frequently changing customer requirements during product and service development, without compromising on quality. However, the adoption of agile and lean approaches in the software industry has brought about challenges in the management of products and services in companies' portfolios [8,9,4]. Kalliney [9] reports on the lack of awareness of the impacts of agile and lean approaches to portfolio management when a company begins to adopt them. Over time, as agile and lean approaches become assimilated in the company, 'portfolio problems', such as difficulties in implementing company's vision and managing cross-team risks and dependencies, become more visible [9]. Additionally, as software companies often embark on concurrent development of multiple offerings that exhibit high interdependency across different software products [10], the process of managing interdependencies and synergies becomes more complex as the number of shared software components increases and development projects expand. The latter according to Kalliney [9], goes beyond simply having teams and managers attend each other's sprint reviews. One possible approach, especially prominent in project-based organizations (PBOs), is to use project portfolio management for selecting, prioritising and evaluating the development of multiple offerings that takes into consideration synergies and interdependencies among projects [11].

How to cite

Ahmad MO, Lwakatare LE, Kuvaja P, Oivo M, Markkula J. An empirical study of portfolio management and Kanban in agile and lean software companies. J Softw Evol Proc. 2017;29: e1834. https://doi.org/10.1002/smr.1834 
Successful implementation of portfolio management in a company helps in the alignment of initiatives with the company strategy. Further, portfolio management allows the use of reliable metrics to effectively interpret market demands and customer requests, rather than managers merely using ad hoc feedback mechanisms to get input from sales and customer representatives [9]. Using portfolio management can, therefore make companies more alert to the offerings in their company portfolio.

The tools and methods used in portfolio management have been well established in the literature on R\&D management [12], information systems (IS) [1] and project management. However, evidence of their application in the context of agile and lean software development literature is scarce $[3,4,5,6]$. In the last decade, there has been growing interest in portfolio management in agile and lean software development $[7,9$, 10]. Adopting traditional portfolio management tools and methods in agile and lean software companies poses challenges due to the dynamic nature of development methods $[8,9]$. The latter leads to a situation where two different approaches that are contradicting are used in combination (i.e. agile and lean approaches are used in combination with traditional portfolio management). Traditional portfolio management, does not take into consideration the operability of agile and lean operations since it often involves a centralised decision making process with detailed annual plans giving an impression of waterfall milestones. On the other hand, the nontraditional portfolio management, that are used in agile and lean software companies, tends to focus on decentralised decision making with light weighted planning of product and service development activities [14]. Various approaches have been proposed to help scale agile methods for portfolio management $[4,9,14$, 17,18]. However, despite these various approaches, software companies are still facing various problems in portfolio management, such as lack of visibility for offerings about to enter the development pipeline, and their effective prioritisation since some of the offerings maybe induced 'under the hood' by some managers [4]. To address some of these problems, Leffingwell [14] points out that by using Kanban for portfolio management, companies can make their business initiatives and offerings significantly more visible to relevant stakeholders. However, there is a lack of empirical evaluation of this suggestion and more importantly studies that evaluate combinatory existence of traditional portfolio management tools and methods and agile and lean approaches in software companies.

According to leading agile and lean experts, such as Anderson and Arne [13], Leffingwell [14] and Shalloway [15], Kanban holds the promise of being one of the easiest, most visual portfolio management tools. Kanban entered into software development in 2004, when David Anderson introduced it in practice while assisting a software development team at Microsoft [16]. Kanban in Japanese means 'visual card'. In software development, a Kanban board shows the current status of all tasks. Kanban has five core principles: 1) visualise workflow; 2) limit work in progress (WIP); 3) measure and manage flow; 4) make process policies explicit; and 5) use models to recognise improvement and opportunities [16]. The biggest benefit of using Kanban is visualisation, which provides a concise overview of all of the company's offerings, along with information about each one. However, the existing proposed frameworks, techniques and methods $[4,9,17,18]$ for portfolio management lack empirical evidence for their use $[5,10,14,19,20]$.

The aim of this study is to gain insights of what traditional portfolio management tools and methods are applicable in portfolio management of agile and lean software companies. The study addresses the following research questions through review of traditional portfolio management literature and interviews with managerial level practitioners from seven software companies.

- RQ1. What are the main traditional portfolio management methods and tools reported in the literature?

- RQ2. What tools and methods are used to manage portfolios in lean and agile software companies?

- RQ3. How does portfolio management in agile and lean software companies differ from traditional portfolio management?

- RQ4. What is the role and potential for the use of Kanban in portfolio management for agile and lean software companies?

The paper is structured as follows: Section 2 provides an overview of the related work on portfolio management in agile and lean software companies, Section 3 describes the research methodology, Section 4 presents the results from the literature review, Section 5 presents results from case companies, Section 6 and 7 discusses the comparison of portfolio management tools and methods in literature and company practice along with Kanban use in portfolio management, Section 8 discusses validity and reliability of the study, and finally Section 9 presents the discussion, conclusion and directions for future work. 


\section{PORTFOLIO MANAGEMENT IN AGILE AND LEAN SOFTWARE COMPANIES}

Software companies are often described as PBOs, since they use projects as a means to develop products and services $[11,21]$. The shift to a more strategic perspective in choosing between projects and tackling the challenge between "doing projects right" and "doing the right projects" has led to the implementation of portfolio management in many PBOs $[11,23,42]$. The literature on portfolio management contains a significant contribution from research in R\&D management, IS and project management $[1,12,26]$. In IS, portfolio theory was introduced by McFarlan in 1981, where he proposed that management employ a riskbased approach to selection and management of IT project portfolios [1]. The focus of portfolio management in IS has mostly been on operational investments rather than on products and services developed for customers [1]. Numerous research contributions have been made to portfolio management in the area of R\&D management and product management, specifically in new product development $[2,12,27,28,29]$, but very often these studies have not paid specific attention to the nature of the products and services making up the portfolios, such as software. The lack of such specific focus on software products led to findings such as inapplicability of the proposed portfolio management tools and methods in software projects [26]. On the other hand, over the past few years, there has been increasing interest in and research conducted on portfolio management specific to software products and services, due to the unique characteristics of software products such as ease of making changes after release $[4,9,10,6]$. In software product management, portfolio management is identified as an important component of product management, along with others such as product road-mapping, requirements management and release planning [30, 31].

Portfolio management involves a dynamic decision-making process for new and existing products, as well as lifecycle management of products based on market trends, product strategies, and so on [2]. The process is significant for ensuring that the value of investments is maximised, limited resources are distributed effectively, and that investments are aligned with overall corporate objectives and goals [2]. To maximise the value of investments under conditions of high risk, the portfolio concept advocates selecting and constructing a portfolio of items (such as products) that collectively yield high expected returns at low risk [1]. Several research contributions describe how portfolio management process ought to be implemented in practice. The most well-known of these include the work of Cooper et al. [2, 27, 28, 33] and the guidelines provided by the Project Management Institute [34]. Successful implementation of portfolio management means achieving the following four main goals [2, 27, 28, 33]: (1) maximising the financial value of the portfolio, (2) linking the portfolio to strategy, (3) balancing the portfolio on relevant dimensions, and (4) ensuring that the total number of ongoing offerings is feasible. To achieve these goals and allow for rational decisions, various methods and tools are used to provide decision-makers with information regarding the optimal set of alternatives to select from, which is complemented by tacit knowledge for assessment of other contextual factors that cannot be computed [1].

Adopting traditional portfolio management is challenging for agile and lean software companies $[4,5,8,9]$. In contrast with the iterative nature of agile methods, traditional portfolio management constitutes a linear process, which also views development as a separate phase to identifying, prioritising, allocating, balancing and reviewing the offerings in a portfolio [4]. In that sense, the frequent re-evaluation of offerings during development challenges the traditional linear process of portfolio management practice [20]. Moreover, agile and lean approaches help to tackle uncertainty in software development through incremental delivery of product features, such as delivering a minimum viable product to customers.

To tackle tensions between traditional portfolio management and agile and lean approaches, scholars [5, 14, 20] have proposed agile portfolio management frameworks. According to Anderson [13], empirical evaluation of agile methods in portfolios and the implementation of the proposed frameworks are scattered. Hodgkins and Hohmann [35] report that Scrum backlogs were insufficient for addressing business needs, and introduced roadmaps as a filter to aid backlog prioritisation and to communicate strategic intent and business opportunities between product managers and the technical team. Vähäniitty [5] discusses agile product and portfolio management in the context of small software organizations, and proposes a framework that shows three key processes that should connect business and development decision-making are product road-mapping, release planning and different levels of portfolio management [5]. This framework offers transparency for business priorities while enabling the just-in-time elaboration required by agile software development [5]. Based on agile principles, Krebs [36] proposes a dynamically managed portfolio with flexible financial 
models. He divides portfolio management into project, resource and asset portfolio management [36]. Krebs suggests to use dashboard for assessing the overall situation of all projects, while for individual projects quality and team morale are the key metrics. Krebs also presents project portfolio management challenges, including too many active projects and an incorrect mix of projects in the portfolio [36].

With respect to the four main goals of portfolio management identified by Cooper et al. [33], agile and lean software companies maximise their portfolio through continuous formulation, estimation and prioritisation of items in the portfolio backlog [14]. Agile and lean approaches emphasise the ability to add or remove items even at the last minute, and provide the possibility of evaluating the business potential of an offering on a smaller scale [9]. According to Bhattacharya et al. [37], in a highly dynamic business environment, product definition is resolved through 'frequent, repeated interactions with customers, and [by] using a flexible development process'. Agile methods have often addressed the latter. To ensure company vision and strategic alignment in portfolio management, software companies that are using agile approaches tend to emphasize the business value of software features. For instance, Ultimate Software [5] decided to use a standard numeric measurement where members assign values and rankings to each high feature, based on specific criteria such as the feature's importance to the market [5]. Similarly, the technologies division of the New York Stock Exchange [6] used a portfolio management technique to assess each feature in their backlog with regards to its relative business value to customers, using a high-medium-low scale. A relative cost for each feature was also calculated.

Leffingwell [14] describes, in his scaled agile framework, several practices to implement agile methods at enterprise scale. He divides his framework into portfolio, program and team levels. At the portfolio level, the company's executives maintain the portfolio vision, allocate resources to value streams through investment themes, and define and prioritize their portfolio backlog, the highest-level mechanism and artefact holding business, and technology development initiatives. According to Abrantes and Figueiredo [10], it is important to enable a centralised view, giving visibility to all ongoing and planned work given limited resources. Such visibility makes it possible to ensure that companies do not underutilise or over-utilise their resources. Lean approaches such as Kanban have enabled companies such as YLE to bring visibility and awareness to all ongoing development activities, facilitating ease of management of project dependencies and pipeline [3]. According to Leffingwell [14], Kanban is very effective for such purposes. Kanban helps in giving visibility to the work process, limiting WIP, communicating priorities and highlighting bottlenecks [16, 38, 47, 48]. The motivation behind visualisation and setting limitations on WIP is to identify the constraints of the process and to focus on one item at a time. This results in a constant flow of work items being released to customers [38, 39, 47, 48]. Multiple "swim lanes" on the Kanban board help a company to visually present, organise and track down offerings in its portfolio, along with a visually depicted value stream for all offerings. According to Anderson and Roock [13], Kanban is particularly beneficial for large companies because changes are made in small increments, and because of its similarities with lean approaches. In a nutshell, Kanban aids portfolio management, brings visibility to the entire portfolio of offerings, speeds up implementation, and helps decision-making while handling multiple offerings with a given set of resources [13, 15, 40]. Furthermore, Leffingwell [14] describes the following five Portfolio Kanban states that a new offering passes through before it can be implemented or rejected:

1. The capture state, where all new ideas are welcome.

2. The review state, where preliminary estimates of opportunity, effort and cost of delay traditionally take place.

3. The analysis state, where more thorough work is done to establish viability, measurable benefit, development and deployment impact, and potential availability of resources. In this stage, a lightweight business case is developed to gain approval for the offering.

4. The portfolio backlog state, where the offerings have made it through the Portfolio Kanban with 'go' approval, and they await the 'pull' from the implementation units or teams.

5. The implementation state, where the approved offerings are allocated to the available teams with the resources and skills necessary for implementation. Offerings are subsequently tracked using various portfolio metrics, such as: the Portfolio Kanban board, Net Promoter Score (NPS), team- and programlevel self-assessment, employee survey, feature cycle time, number of releases per year, defect data, and support call volume, partner and vendor surveys. 


\section{METHODOLOGY}

The study was carried out in two phases. In the first phase, traditional portfolio management tools and methods were investigated in the literature using snowballing technique. In the second phase, interviews were conducted with experts from agile and lean software companies. The reasons for choosing these methods are explained in the subsections below. Finally, we compared tools and methods presented in the traditional portfolio management literature with those used in selected agile and lean software companies, according to four goals of portfolio management.

\subsection{Literature review}

A literature review was conducted first in order to identify portfolio management tools and methods using a snowballing technique [41]. Snowballing - using the reference list of a paper and the citations to the paper to identify additional papers - was found to be a suitable systematic approach for this exploratory research. According to Wohlin [41], using snowballing as a first search strategy may be a good alternative to the use of database searches. The motivation for choosing a snowballing technique for the literature review [42] was to collect all necessary relevant literature without performing a full, systematic literature review, as the topic of 'portfolio management' is very broad and established in various disciplines. Snowballing offers a good coverage of the investigating area or topic and it is less influenced by the amount of noise from digital libraries searches [43]. Further, according to Jalali and Wohlin [43], systematic literature reviews require separate formulation for each database, whilst snowballing does not explicitly require searching in more than one database. They add that snowballing is more understandable and easy to follow, particularly for novice researchers; whereas systematic literature review provides more guidelines, which novice researchers might find confusing rather than helpful [43].

Webster and Watson [42] recommended using both backward snowballing (working from the reference lists) and forward snowballing (finding citations to the papers). In a study conducted by Jalali and Wohlin [43], upon comparing the results of database search reviews with backward snowballing reviews, the findings were that the actual results are not highly dependent on the search strategy. In this study, after the first literature search, only backward snowballing used. In each process, the first two researchers reviewed and selected papers together. Figure 1 shows our complete process of literature review.

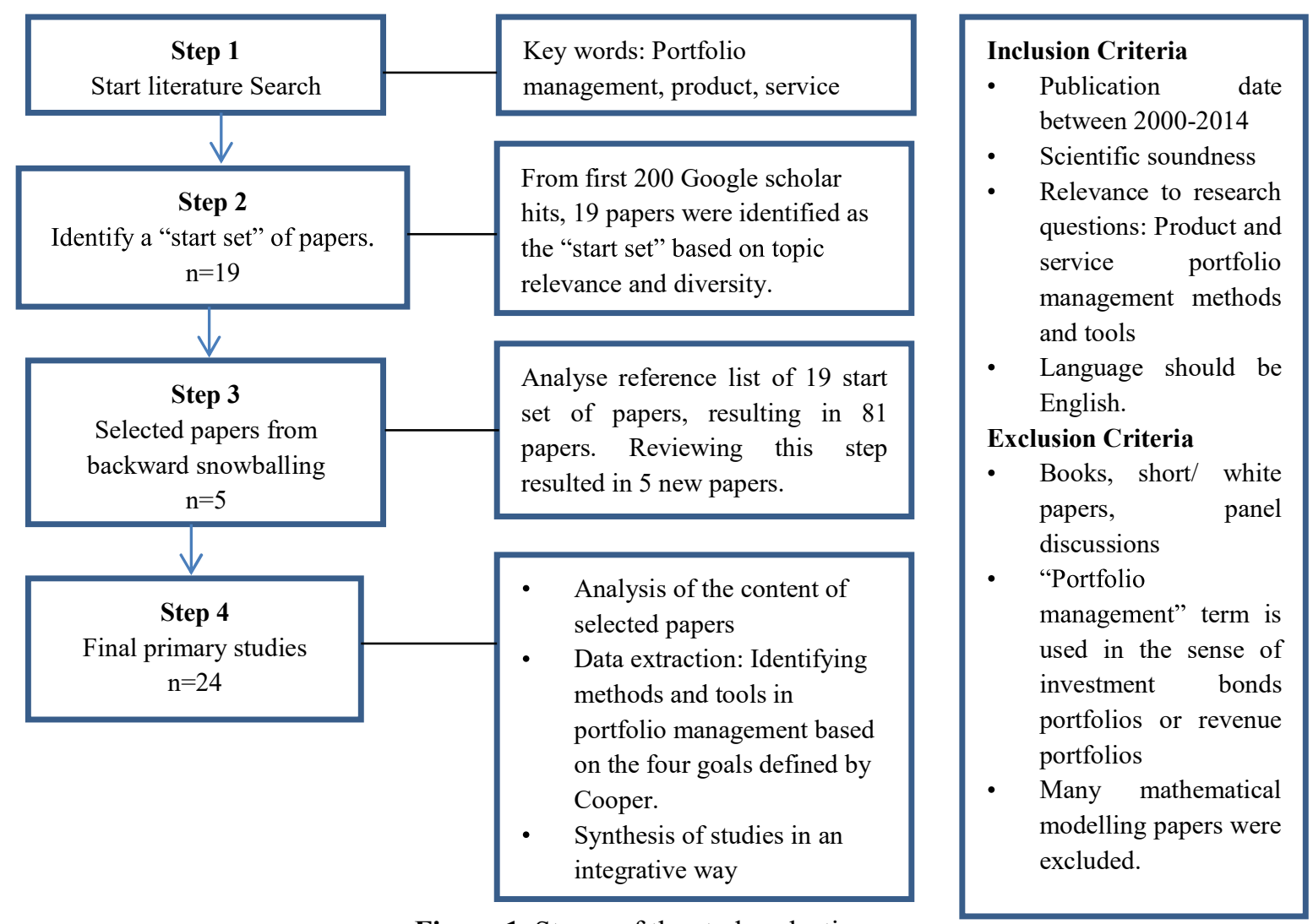

Figure 1. Stages of the study selection process 
The first step of our search involved finding relevant papers in Google Scholar using a selected general keywords ('portfolio management', 'product', 'service'), published from 2000 to 2014. According to Wohlin [41], a good starting point may be identified by using the Google Scholar search engine, which helps to avoid any bias toward researchers or any specific publisher. The generic and broad keywords were selected based on key terms that relate to our research as expressed in the research questions. The key term 'portfolio management' was selected based on our understanding of the topic from most popular cited portfolio management studies. To limit studies to only those that focus on portfolio rather than projects or programs thus giving a narrower search of studies that fall under our topic of interest. The use of 'product' and 'service' keywords were aimed to exclude studies that focus on other types of portfolio assets such as financial bonds without necessarily limiting our search to the nature of the products and services such as software. While we do not claim that this would result to the inclusion of all relevant studies, the researcher saw that it is reasonable to use this combination would give important studies that are also representative of traditional portfolio management studies. Moreover, as specified by Jalali and Wohlin [43], the efficiency of snowballing might be higher when the keywords for searching include general terms. From Google Scholar search results, we selected the first 200 search results from which 19 papers were identified as relevant since their inclusion focused on those that reported portfolio management of products and services. We then proceeded to call these relevant papers as 'start set papers'. The start set papers spanned from several different publishers, authors and across the years.

In the second step, we started backward snowballing by going through the reference lists of our 'start set papers'. For each paper of the start set papers, we read the publication title from the reference list and included relevant studies. This process resulted into the selection of 81 papers. Two researchers read all titles and abstracts, and checked the inclusion and exclusion criteria for each entry from the first and second step of the review. Finally, we identified 24 primary studies out of 281 . We analysed and classified the selected studies according to type, tools and methods used for portfolio management. The identified portfolio management tools and methods were then categorised according to the four portfolio management goals identified by Cooper et al. [33].

\subsection{Interviews}

In the second phase of the study investigated the tools and methods used by agile and lean software companies to manage their portfolios by conducting face-to-face semi structured interviews with key informants from the selected companies. In our previous studies [7, 38, 39, 47] these selected companies were identified as blending agile and lean approaches (such as Scrumban) in various units of their respective companies. This allowed us to collect rich data while keeping the flexibility necessary for an exploratory study. According to Runeson and Höst [44], semi-structured interviews allow for improvisation and exploration of the studied objects. Prior to contacting the key informants, we selected companies based on convenience sampling. However, the companies also needed to be using agile and lean approaches. As a result, seven software companies from the N4S Program were selected for the study, as they were actively using agile and lean approaches [7, 38, 39, 47].The N4S program was initiated in 2014, involving 14 large industrial organisations, 18 SMEs and 10 research institutes and universities.

The key informant technique [45] was adopted in selecting company representatives for the interviews, as it allowed us to focus the interviews on highly knowledgeable individuals. The key informant technique is meant to identify key experts from whom rich and high quality data may be acquired. The large multinational companies in N4S program share key characteristics, in that they are transforming their way of working based on agile and lean approaches, and in the respondents' roles and work experience. We first contacted company representatives from the N4S consortium and discussed the goals and objectives of the study. Thereafter, the contacted company representative identified and suggested suitable candidates to be interviewed from their respective companies based on the person's work experience, knowledge of agile and lean approaches and their participation in portfolio management related activities.

We interviewed a total of eight candidates (hence forth referred as key informants) that were proposed by contacted company representatives from the N4S consortium. The key informants were higher management senior people, actively taking part in portfolio management activities in their companies. One key informant from each company was invited to take part in the study; all agreed to participate. In total, there were seven interviews with one interviewee from each company, except for one company that had two key informants. The eight interviews resulted in a total of 582 minutes of recorded material and 50 pages of interview transcripts. Although this sample cannot be representative of the entire population of software companies, the interviews yielded rich data about portfolio management from seven companies. Using the key informant technique assures that the interviewees are experts who participate in portfolio management activities within 
their respected companies. Detailed descriptions of the interview participants and their roles are shown in Table 1.

Table 1. Companies and roles of interviewed participants

\begin{tabular}{|c|l|l|l|}
\hline $\begin{array}{c}\text { Company } \\
\text { ID }\end{array}$ & \multicolumn{1}{|c|}{ Primary domain } & $\begin{array}{c}\text { No. of } \\
\text { employees in } \\
\text { the company }\end{array}$ & \multicolumn{1}{|c|}{ Roles of interviewees (years in company) } \\
\hline A & Computer security & $>900$ & $\begin{array}{l}\text { 1. Director of External R\&D collaboration }(8 \text { yrs. }) ; \\
\text { 2. Senior Manager for Quality of Operations (4 yrs. })\end{array}$ \\
\hline B & $\begin{array}{l}\text { Software and Systems (specialising } \\
\text { in embedded systems) }\end{array}$ & $>1000$ & $\begin{array}{l}\text { 1. Head of Quality and Environment, and Strategy } \\
\text { Process Facilitator (12 yrs. })\end{array}$ \\
\hline C & IT services and consultancy & $>75$ & 1. CEO and Co-founder (13 yrs.) \\
\hline D & Telecom network & $>45,000$ & 1. Business Improvement Manager $(>20$ yrs. $)$ \\
\hline E & IT and product engineering services & $>14,000$ & 1. Senior Solutions Consultant $(>9$ yrs. $)$ \\
\hline F & Telecom network & $>25,000$ & $\begin{array}{l}\text { 1. Internal Coach for Agile and Lean Organisational } \\
\text { Transformation (> 20 yrs.) }\end{array}$ \\
\hline G & Services and consultancy & $>250$ & 1. Agile, Lean and Kanban Consultant Coach (2.5 yrs. $)$ \\
\hline
\end{tabular}

According to Runeson and Höst [44], researchers should formulate a research question that includes potentially important variables; however, they should avoid linking variables and theories as much as possible. Based on the literature we had researched [4, 5, 9, 10, 20, 32], we created a protocol for semi-structured interviews which covered the four research themes: (1) tools and methods for portfolio management in general; (2) tools and methods for ensuring balance in the portfolio; (3) tools and methods for ensuring that the portfolio reflects business strategy; (4) tools and methods for ensuring a proper number of projects against organisational capacity. In addition, for each theme, the role and potential use of Kanban was also explored, as software companies are increasingly using Kanban for various organisational levels and teams.

The interview guide was piloted with one expert from the software industry and three researchers. At least two researchers participated in all interview sessions. At the start of each interview session, the objectives of the study and definitions of key terminologies were presented to the interviewees. All interviews were audiorecorded and notes were also taken. The audio recordings were transcribed and sent back to all interviewees to review and validate their responses.

Interview transcripts were analysed using template analysis developed by King [46] with Nvivo, a qualitative data analysis software. Template analysis is a systematic technique for categorising qualitative data thematically. Template analysis was chosen because it allows a priori themes to be used to help develop an initial version of the coding template. An initial interview template was constructed using the four previously mentioned portfolio management goals. Interview data was then mapped onto the initial template, modifying it further until all relevant data was coded. The process was concluded by applying the final version of the template to the data as a whole, and a priori themes were redefined or discarded if they did not prove helpful in capturing key details from the data.

\section{RESULTS FROM THE LITERATURE REVIEW}

In the literature review 24 relevant papers were identified. The papers discussed portfolio management methods and tools. Nineteen primary studies (S1-S19) were selected from the Google Scholar search and five (E1-E5) from backward snowballing (see Appendix A). The topic of portfolio management was found in a wide variety of journals and conferences, as seen in Table 2 below. These studies discuss various methods and tools for managing portfolios of offerings. 
Table 2. Primary studies and publication forums

\begin{tabular}{|l|l|l|}
\hline \multicolumn{1}{|c|}{ Publication forum } & Publication & Research strategy \\
\hline \multirow{4}{*}{$\begin{array}{l}\text { International Journal of Quality \& Reliability } \\
\text { Management }\end{array}$} & {$[\mathrm{S} 9]$} & Case study \\
\cline { 2 - 3 } & {$[\mathrm{S} 10]$} & Survey \\
\cline { 2 - 3 } & {$[\mathrm{S} 17]$} & Case study \\
\cline { 2 - 3 } Research Technology Management & {$[\mathrm{E} 4]$} & Case study \\
\cline { 2 - 3 } & {$[\mathrm{S} 4]$} & Case study \\
\cline { 2 - 3 } & {$[\mathrm{S} 5]$} & Case study \\
\cline { 2 - 3 } & {$[\mathrm{S} 6]$} & Case study \\
\hline \multirow{3}{*}{ Journal of Product Innovation Management } & {$[\mathrm{S} 1]$} & Survey \\
\cline { 2 - 3 } & {$[\mathrm{E} 3]$} & Survey \\
\hline \multirow{2}{*}{ Management Science } & {$[\mathrm{S} 2]$} & Case study \\
\cline { 2 - 3 } & {$[\mathrm{E} 1]$} & Literature review \\
\hline IEEE Transaction on Engineering Management & {$[\mathrm{S} 8]$} & Literature review \\
\hline Portland International Center for Management of & {$[\mathrm{S} 11]$} & Case study \\
\hline Engineering and Technology Proceedings & Literature Review \\
\hline Australasian Conference on Information Systems & {$[\mathrm{S} 12]$} & Literature review \\
\hline International Journal of Project Management & {$[\mathrm{S} 13]$} & Literature review \\
\hline Technological Forecasting and Social Change & {$[\mathrm{S} 15]$} & Case study \\
\hline International Journal of Management Reviews & {$[\mathrm{S} 16]$} & Literature review \\
\hline Computers \& Industrial Engineering & {$[\mathrm{S} 18]$} & Survey \\
\hline Technovation, Elsevier Science & {$[\mathrm{S} 14]$} & Case study \\
\hline Journal of Marketing Research & {$[\mathrm{E} 5]$} & Theoretical modelling \\
\hline Decision Support Systems & {$[\mathrm{S} 19]$} & Case study \\
\hline Operation Management & {$[\mathrm{E} 2]$} & Theoretical framework \\
\hline R\&D Management & {$[\mathrm{S} 3]$} & Multiple-case study \\
\hline
\end{tabular}

Portfolio management practices have a strong base in R\&D management and in managing (PBOs) [S10]. From this perspective, our research focuses on the tools and methods used to evaluate and manage new and existing products and services, including R\&D projects. The results from the literature review showed that a variety of portfolio management tools and methods have been proposed in traditional portfolio management literature for selection of offerings and resource allocation to new and existing offerings.

To answer RQ1, the results of the literature analysis are synthesised according to four main goals of portfolio management: to maximise the value of the portfolio; to ensure a balance among portfolio initiatives; to achieve strategic alignment of the portfolio; and to pick the right number of projects. Table 3 presents a summary of the identified, selected and analysed studies.

Table 3. Traditional portfolio management tools and methods in literature

\begin{tabular}{|c|c|c|c|}
\hline $\begin{array}{l}\text { Main goal of portfolio } \\
\text { management }\end{array}$ & \multicolumn{2}{|r|}{ Traditional portfolio management methods } & Literature \\
\hline \multirow[t]{2}{*}{$\begin{array}{l}\text { Maximise the value of } \\
\text { the portfolio }\end{array}$} & Financial models & $\begin{array}{l}\text { Real Options Analysis, Payback Period (PBP), } \\
\text { Productivity Index (PI), Decision Tree Analysis, Net } \\
\text { Present Value (NPV), Return On Investment (ROI), } \\
\text { Internal Rate of Return (IRR), Discounted Cash Flow } \\
\text { (DCF), Options Pricing Theory (OPT), Earned Value } \\
\text { Analysis (EVA), Expected Commercial Value (ECV) }\end{array}$ & $\begin{array}{l}\text { S19] [S1-S8] } \\
{[\mathrm{E} 1-\mathrm{E} 4][\mathrm{S} 10-} \\
\text { S13] [S15-S17] }\end{array}$ \\
\hline & $\begin{array}{l}\text { Multi-criteria } \\
\text { decision models }\end{array}$ & $\begin{array}{l}\text { Fuzzy logic, Delphi model, Market potential, Scoring } \\
\text { models \& checklists, Analytical Hierarchy Process } \\
\text { (AHP) }\end{array}$ & $\begin{array}{l}{[\mathrm{S} 1][\mathrm{S} 3-\mathrm{S} 8][\mathrm{E} 2-} \\
\mathrm{E} 5][\mathrm{S} 10-\mathrm{S} 13] \\
{[\mathrm{S} 15-\mathrm{S} 19]}\end{array}$ \\
\hline $\begin{array}{l}\text { Ensure balance among } \\
\text { portfolio offerings }\end{array}$ & $\begin{array}{l}\text { Mapping and } \\
\text { matrix approaches }\end{array}$ & $\begin{array}{l}\text { Bubble diagram, Portfolio matrix, McKinsey matrix, } \\
\text { BCG matrix }\end{array}$ & $\begin{array}{l}{[\mathrm{S} 1][\mathrm{E} 3][\mathrm{S} 3]} \\
{[\mathrm{S} 4][\mathrm{S} 6-\mathrm{S} 14]} \\
{[\mathrm{S} 18][\mathrm{S} 19]}\end{array}$ \\
\hline $\begin{array}{l}\text { Achieve strategic } \\
\text { alignment of the } \\
\text { portfolio }\end{array}$ & $\begin{array}{l}\text { Strategic } \\
\text { approaches }\end{array}$ & $\begin{array}{l}\text { Strategic buckets and maps, Product-technology } \\
\text { roadmaps }\end{array}$ & $\begin{array}{l}{[\mathrm{E} 4][\mathrm{S} 1-\mathrm{S} 7][\mathrm{S} 9-} \\
\mathrm{S} 11][\mathrm{S} 15][\mathrm{S} 19]\end{array}$ \\
\hline $\begin{array}{l}\text { Pick the right number } \\
\text { of offerings }\end{array}$ & Capacity analysis & $\begin{array}{l}\text { Pipeline management, Resource capacity analysis, } \\
\text { Rank ordering projects }\end{array}$ & {$[\mathrm{S} 1-\mathrm{S} 7][\mathrm{S} 11]$} \\
\hline
\end{tabular}


Maximising the value of the portfolio means allocating resources to offerings according to business objectives, in order to increase the expected return on investment. Such business objectives could be profitability, strategy and acceptable risk. To evaluate portfolio for value maximisation, companies need to identify select right projects using financial models as well as maintain and make sure the intended benefits will be realised [S1S8]. For this purpose, the portfolio is constantly evaluated (minimum twice a year) and actions are taken if offerings are not performing at the right level or not aligned to the business strategy.

Financial models are used to quantitatively evaluate the economic return on new project ideas, while taking into consideration the income flow and time dependency of an investment. Financial models such as ROI, NPV, PI, IRR, payback analysis, and Discounted Cash Flow have been popular portfolio management tools for value maximisation [S1-S8, E1, E3, E5], while financial models such as options pricing have no evidence of being applied in practice [S11]. Non-financial models such as AHP and scoring models use several criteria to decide on the inclusion of a project in a portfolio, using both quantitative and qualitative techniques to assess individual projects and compare a number of projects with a particular dimension. These models first determine the weightings for different objectives of the company's business, then compute and compare the contributions of the projects to the weighted objectives. AHP is difficult to use because it involves a large number of comparisons, and sudden addition or deletion of a project means starting again from the beginning. This is not the case for scoring models, however, because they use a relatively small number of decision criteria (such as cost and probability of technical success) to determine the merits of a project. Checklists are similar to the criteria of scoring models, but the outcome of checklists is a 'yes or no' answer to the questions, where each project must achieve a certain number of 'yes' answers to proceed or obtain funding [S3]. These financial and non-financial tools and methods should be used with care, because their analysis requires rather detailed estimation and their uncertainty is usually high [S4, S6].

\subsection{Ensuring a balance among portfolio offerings}

Ensuring a balance among portfolio offerings is another important element in portfolio management, since companies typically have a variety of projects. The goal of the portfolio is to achieve a desired balance of offerings by using a number of parameters, such as time (for example, long term versus short term), risk level (for example, high risk versus low risk), and types of markets. Risk level assessment is important when considering portfolio balance in order to avoid over-commitment to high risk projects that may jeopardize the future of the company. To illustrate balance in a portfolio, various graphical techniques are used, such as portfolio maps, bubble diagrams and pie charts [S3, S7, S10, S11, E3]. These tools provide a graphical representation of the current situation of the portfolio and the distribution of resources. Portfolio maps plot proposed offerings on two axes or other matrices to facilitate graphical and visual display [S11, S12]. Commonly used portfolio maps balance risk versus return, and benefits to customers versus competitive advantage [S11]; one example of a popular portfolio map is the Boston Consulting Group (BCG) matrix [S12]. These graphical tools and methods help plan the distribution of resources with respect to the company's capacity. These tools also help to establish an appropriate balance between the offerings in the portfolio. In a balanced portfolio, the need to maximise value is high, and a balanced portfolio helps a company ensure that its portfolio reflects its business strategy.

\subsection{Achieving the strategic alignment of the portfolio}

Achieving the strategic alignment of the portfolio means that all the offerings should be consistently aligned with the company's strategy. It is important that the company's business strategy takes into account both internal and external business factors, in order to build a strategic direction focused on achieving competitive advantage, and to better determine and allocate funds across different types of projects [S3, E4]. According to Cooper et al. [S3], business strategy is the second most popular portfolio approach after financial methods. A number of methods are presented in the literature to align offerings with the business strategy. The most common approaches are 'top down' and 'bottom up'. In the 'top down' approach, companies set aside funds for different types of strategic priorities before project selection, using methods such as strategic buckets and product roadmaps; whereas 'bottom up' approach builds on the philosophy that if good decisions are made for individual offerings, the portfolio will take care of itself [S1-S7, S9]. A strategic bucket equates implementation of strategy with allocation of resources to specific projects (or focus areas) that mirror the 
business strategy; it also improves the alignment of the portfolio with the strategy [S11]. It is used to allocate funds in the overall budget to specific types of projects or focus areas of strategic importance. A survey conducted by Barczak [S1] reported that the strategic bucket is the most frequently used portfolio management method in companies. Other suggested methods and tools include roadmaps [S1-S7, S11, E4].

\subsection{Picking the right number of offerings}

Picking the right number of offerings is essential for portfolio management, owing to limited resources. Too many offerings competing for limited resources results in gridlock in the company's offerings pipeline. To avoid such situations and to have the right number of offerings in the portfolio, various methods such as resource capacity analysis and pipeline management may be used [S1-S7]. Pipeline management focuses on managing offerings by ensuring that resources are not overstretched, and that the development pipeline timing and flow of offerings are managed [S11]. The literature shows that the main benefits of portfolio management are that (a) the portfolio of offerings aligns with the company's strategy, (b) companies use resources in a better way, (c) poorly performing or outdated offerings are terminated, and (d) key offerings are monitored constantly in order to take necessary actions whenever needed.

In summary, to achieve the four goals of portfolio management, decisions on offerings in the portfolio are mainly based on sophisticated quantitative modelling methods, which are derived from financial and operations research. A majority of these financial methods are theoretically well-justified, but have significant practical shortcomings. For example, the absence of accurate data regarding offerings, especially new offerings, makes these methods unreliable. Interestingly, financial methods are popular, and companies rely more on them when making decisions about an offering in the portfolio. In the literature, there is a consensus that there is no single method or tool suitable for all situations [S10]. However, across the literature, there still remains a large gap in understanding what constitutes effective portfolio decision-making to achieve the above-mentioned four goals.

\section{RESULTS FROM EMPIRICAL STUDY}

Altogether, eight interviews were conducted with seven companies which actively use agile and lean approaches. The four main goals of portfolio management defined by Cooper et al. [33] were used as a framework to analyse the collected data from interviews. Table 4 provides an overview of the common portfolio management tools and methods used by agile and lean software companies. 
Table 4. Portfolio management tools and methods in companies

\begin{tabular}{|c|c|c|c|c|c|c|c|c|}
\hline \multirow{2}{*}{$\begin{array}{l}\text { Main goal of portfolio } \\
\text { management }\end{array}$} & \multirow{2}{*}{ Portfolio management methods } & \multicolumn{7}{|c|}{ Company ID } \\
\hline & & $\mathbf{A}$ & $\mathbf{B}$ & $\mathbf{C}$ & D & $\mathbf{E}$ & $\mathbf{F}$ & G \\
\hline \multirow{8}{*}{$\begin{array}{l}\text { Maximise the value of the } \\
\text { portfolio }\end{array}$} & Cost-Benefit Analysis & $\mathrm{X}$ & & & $\mathrm{X}$ & & $\mathrm{X}$ & \\
\hline & DCF & & $\mathrm{X}$ & & & & & \\
\hline & PBP & & $\mathrm{X}$ & & & & & \\
\hline & EVA & & & & $\mathrm{X}$ & & & $\mathrm{X}$ \\
\hline & NPV & & & & & $\mathrm{X}$ & & $\mathrm{X}$ \\
\hline & Cash Flow & & & $\mathrm{X}$ & & & & \\
\hline & $\begin{array}{l}\text { Scoring models, Checklists, e.g. Lead Time, } \\
\text { Value Throughput }\end{array}$ & $\mathrm{X}$ & $\mathrm{X}$ & $\mathrm{X}$ & $\mathrm{X}$ & $\mathrm{X}$ & $\mathrm{X}$ & $\mathrm{X}$ \\
\hline & Product experimentation & & $\mathrm{X}$ & & & $\mathrm{X}$ & $\mathrm{X}$ & \\
\hline \multirow{5}{*}{$\begin{array}{l}\text { Ensure balance among } \\
\text { portfolio offerings }\end{array}$} & Strategic Buckets (Key focus areas) & $\mathrm{X}$ & $\mathrm{X}$ & $\mathrm{X}$ & $\mathrm{X}$ & $\mathrm{X}$ & $\mathrm{X}$ & \\
\hline & Business Roadmap & $\mathrm{X}$ & $\mathrm{X}$ & & & & & \\
\hline & Kanban & $\mathrm{X}$ & $\mathrm{X}$ & $\mathrm{X}$ & $\mathrm{X}$ & $\mathrm{X}$ & $\mathrm{X}$ & $\mathrm{X}$ \\
\hline & $\begin{array}{l}\text { Bubble Diagram, Burn Down Charts, } \\
\text { Cumulative Flow Diagrams }\end{array}$ & $\mathrm{X}$ & & & & $\mathrm{X}$ & $\mathrm{X}$ & \\
\hline & Ad hoc process, matrix & & & & & & & $\mathrm{X}$ \\
\hline \multirow{5}{*}{$\begin{array}{l}\text { Achieve strategic } \\
\text { alignment of the portfolio }\end{array}$} & Strategic goals & $\mathrm{X}$ & $\mathrm{X}$ & $\mathrm{X}$ & $\mathrm{X}$ & $\mathrm{X}$ & & $\mathrm{X}$ \\
\hline & Product Roadmap & $\mathrm{X}$ & $\mathrm{X}$ & & & & & \\
\hline & Kanban & $\mathrm{X}$ & $\mathrm{X}$ & $\mathrm{X}$ & $\mathrm{X}$ & $\mathrm{X}$ & $\mathrm{X}$ & \\
\hline & Key Performance Indicators (KPI) & & $\mathrm{X}$ & $\mathrm{X}$ & & & & \\
\hline & PowerPoint and videos to communicate strategy & & & & & $\mathrm{X}$ & & \\
\hline \multirow{2}{*}{$\begin{array}{l}\text { Pick the right number of } \\
\text { offerings }\end{array}$} & R\&D capacity pipeline analysis & $\mathrm{X}$ & $\mathrm{X}$ & & & $\mathrm{X}$ & & \\
\hline & Capacity or capability planning & & $\mathrm{X}$ & & $\mathrm{X}$ & $\mathrm{X}$ & $\mathrm{X}$ & $\bar{X}$ \\
\hline
\end{tabular}

\subsection{Maximising the value of the portfolio}

To maximise the value of the portfolio, companies employed a variety of tools and methods to evaluate the business potential of all proposed new offerings. The process of selecting and evaluating new offering ideas for inclusion in portfolio pass through several investment decision gates particularly in large companies (such as company A, B, D and F). In these companies, new offering ideas were formally presented as business plan to decision making bodies. In smaller companies (such as company $\mathrm{C}$ and $\mathrm{G}$ ) the process was less formal. The criteria used for evaluating new ideas in decision gates became more 'tight' as ideas went forward in the large companies. New ideas for offerings were mostly evaluated using a combination of financial models with scoring models and checklists. The most common financial models were those that analysed and evaluated the costs and benefits of the new proposed offerings. These methods included ROI in company A; NPV in companies B, E and G; EVA in companies D and G; and cash flow in company C. However, there were some challenges with the use of financial models, and it was evident that all companies used them less because of lack of data, or were used as result of long existing company practice. For example, in company A, costbenefit analyses were derived as rough estimates rather than actual financial metrics as depicted in the following response: 'Honestly, it's very seldom that you have actual financial metrics created as like an exact number or something. There is like a clear, okay, this business goal is going to increase our sales this much. Or for the technology business goal, if we do this improvement, it will result in 15 percent cut in operational costs. So those [financial] numbers exist but exact sales numbers are sometimes very difficult to put into this. Usually there is a kind of rough idea of the business benefit.' Further, in the case of company B, financial models were used due to long-term established company practice over several years: 'We have certain business decision processes which we have used already some six, seven years. For product initiative we normally have understanding of the customers or markets and competition. Then we have business management who is deciding the ownership. We create a collaborated team, initiate financial calculations, product or service concept and then assess the capability for execution. In the financial calculation we have for example discounted value of the proposal, for all development cost, possible markets and etc. It's creating for us [company] that what is the point of [product initiative] and what is the calculation of the payback for the investment.'

All companies make frequent use of checklists containing a list of criteria which new ideas must meet. In company A, criteria such as lead time, customer preferences and industry standards were used to measure and assess offerings at high levels: 'We measure four things on a high level: lead time (how fast things go through 
this flow), value throughput (how much new business is generated through actualisation of the roadmap), net promoter score (how well do customers like your offering) and work in progress count.' Product lead time, customer preference and competitive situation were criteria evaluated by all companies. The companies preferred short lead times, as this encouraged incremental delivery with lowered risk. Other practices such as product demonstrations ('demos') were also increasingly seen to be important, as in the case of company B. Demos help to quickly develop ideas into actual product features before beginning product development efforts: 'When we are starting something, a business plan passes through business idea screening. The idea is grown up by creating a (Hackathon) concept; the purpose is to make a demo for the idea before it goes to the traditional business development cycle.' According to the interviewees, early product demonstrations, customer preferences and satisfaction are crucial portfolio evaluation criteria, both during selection and after delivery of an offering. This is because they serve as important feedback to develop and improve the portfolio by directing software product development activities. Companies A and D used NPS and usability surveys, respectively, to gather customer preference and satisfaction data. Product experimental practices and good customer relationships help service companies (such as company $\mathrm{G}$ ) to identify and determine new services to be ramped-up: '[for example] two years ago we ramped up a concept and visual design service just because we found out that customers keep asking for it and are buying it from other people. Then there are highly experimental services like the [X service] for embedded software that we thought might be a great market. So we actually created a service to support that market.' It was therefore indicated that agile and lean software companies place more emphasis on non-financial models, such as lead time, customer satisfaction and quality of offerings.

Interestingly, less mentioned financial methods are taken in consideration in case of small services company ' $\mathrm{C}$ ': 'Cash flow situation is very important for us to understand because it shows us our profit level and how much effort we can put on product development. For the new things we see that what progress we have made, what we have learned, the competition and most promising things we need to continue to develop. New features, is it something that we want to stabilise the product, is it that we are looking for a pilot customer that would be able to test it in a real production. So if we have something ready but we cannot find a pilot customer, it can take one year to move on.'

\subsection{Ensuring a balance among portfolio offerings}

According to the interviewees, ensuring a balanced portfolio is facilitated through inputs from the business strategy and roadmap. Prior to the selection of new ideas, resources were first distributed and allocated annually according to key focus areas (or business units), which corresponded to the business strategy of the company. In business roadmaps key focus areas were observed to have great importance in companies developing embedded systems (companies A, B and F). This is because high competition, an increased need for short lead time, and operating in a business-to-business environment require that the customer be informed in advance about the features and benefits of new product releases. This was achieved by using product roadmaps that were shown to customers such as network operators. As the interviewee from company F put it: 'The competition in our business is quite tough. I believe that each of the vendors is taking a high risk. [Customers] are picking the company that shows the most attractive roadmap. The roadmap in [our company] is in supported technologies. The [customer] wants to understand when certain new releases are coming out, and what are the main new functionalities or benefits for the [customer]. The main reason for that is the rollout time for the [customer], when compared to easy software products. You just download [those].' To ensure balance among the portfolio offerings interviewee express it as: 'we balance and visualise the stuff that we do [for example using] cumulative flow diagrams and Kanban. Kanban always finds the balance between demand and capability. .... Kanban doesn't help in balancing the portfolio but it somehow signals that, e.g. the working pipeline is full, and, in turn, helps to evaluate suitable available options at that given time to take necessary actions.'

\subsection{Achieving strategic alignment of the portfolio}

All interviewees mentioned that their development and delivery of offerings were driven by the company's business strategy. The business strategy was identified as an important factor which defines the main business areas into which offerings and investment resources were streamlined. Firstly, business strategy facilitates the initial allocation of resources according to prioritised main business areas that realise the company's portfolio. This was particularly evident in all companies, as an interviewee in company A elaborated: 'We have classified 
different business lines (each business line is responsible for their own portfolio management and R\&D) in terms of their strategic importance. This means that the different business lines are given certain weight in the company-level investment. As a result each business line operates under their own investment which comes from the strategy.' Secondly, new and existing offerings in the portfolio are streamlined and constantly reevaluated (minimum twice a year) on the basis of the company's business strategy: 'We have a business strategy and based on it, we do products or offerings', and 'we have a combination of some of the focus areas [strategic goals specify it]... Our offering is one of the first ones that make the strategy real.' Along with the existing strategy, companies are constantly considering and incorporating future strategic directions into current business opportunities, rather than merely doing the same things: 'We are trying to make room for future strategic goals and their fulfilment. At our company and I also believe this is common for others also that it's easy to keep doing the same thing that you have done before, and then in the end you will then have so much work to do just to keep the machine running without thinking that, does it make sense economically.'

To achieve strategic alignment of the portfolio, it was identified that companies need to effectively communicate their strategy across the entire company, as well as frequently reviewing the strategy, for example, on a quarterly or annual basis. Company A and B reported that they construct roadmaps from their strategic plan to visualise what projects will be undertaken and what products will be delivered in the near future. To achieve strategic alignment of the offerings, company B used Kanban as a tool for the execution of all offerings. An interviewee explained it like this: 'Kanban, for us, is a tool for the execution [of business strategy]. We use JIRA Kanban.' In agile and lean software companies, techniques used to communicate the strategy throughout the company included PowerPoint presentations, short videos, monthly meetings, magazines, and drawing the big picture on the walls for each unit.

\subsection{Picking the right number of offerings}

Software companies found it important to use tools and methods for estimating workload, rather than specifying a number of products and services. Tools and methods to estimate the workload for the development of proposed product or service features helped determine their release dates, associated risks and capacity planning. For example, one interviewee said: '[There is] no limit on new initiatives; they are stored in the [portfolio] backlog. We take everything that we find to be reasonable and nice to have in the portfolio-level product backlog for these [existing] products. Then, we get realistic about what we can do; we try to estimate the effort required for new ideas. We then have a kind of velocity for the team, and if it seems that there is a lot of stuff [to do], we prefer to get another team. So we don't want to say "No new ideas for now, because our team capacity is used up for next year". Instead, we try to say "Please give us any new ideas you have", and then we try to negotiate for instance, it is possible to get another team."

All software companies place emphasis on team effort planning, which involves balancing the required effort with available resources during the development and delivery of offerings. This is because, in service companies (companies $\mathrm{C}, \mathrm{E}$ and $\mathrm{G}$ ), employees are working on multiple projects at the same time; and product companies (companies A, B, D and F) it is need to ensure that the company has enough resources to match portfolio needs at all levels. This is evident from the following extract from an interview: 'On the portfolio level, we break things down into the product level and match them with our capabilities. This helps to plot which teams are involved in which development [product project] and able to see which team will be free at which point of time, and we can plan accordingly for the upcoming features.' Teams' feedback proved to be particularly important in the context of agile software development, as it helps speed up product development activities by mitigating the challenges associated with the process of adjusting resources. On a more abstract level, this also drives companies to seek and place emphasis on people with broad competencies to increase the company's ability to make quick changes while maintaining the balance in portfolio: 'We build an organisation where we can make very quick moves and changes capability-wise. Any portfolio change triggers capability thinking [meaning] whether we handle the change. We have teams and people that are capable of doing a very broad scale of things.' Some of the challenges experienced by companies in the process of adjusting resources included the need to hire employees with new competencies for service companies (companies $\mathrm{G}$ and $\mathrm{C}$ ), and making requests to higher levels of the hierarchy. This latter process can be slow and painful, as expressed by the interviewee from company E: 'usually, scaling resources up or down is a very slow and, sometimes, costly and painful process. So we try not to do that too rapidly.' Another interviewee mentioned that: 'Kanban brings more clarity to activities, helps in identifying high-priority work and resource allocation, helps management to select high-priority activities and to decide where to put more (or less) effort for the organisation to survive.' 
In summary, portfolio management in agile and lean software companies is a challenging undertaking. Some of the challenges mentioned by interviewees included: 1) It was difficult to determine the long-term and short-term value of proposed initiatives; 2) Multiple offerings in the portfolio, as well as the increasing number of proposed initiatives, made it difficult to prioritise and balance them against available capacity; 3) Most importantly, balancing the time factor was challenging for the companies, mainly because the portfolio was constantly exposed to change and evolution. As such, there was a need for dynamic tools and methods that would help to break down strategic decisions and goals and link them to the portfolio of products and services and daily tasks.

\section{COMPARISON OF PORTFOLIO MANAGEMENT TOOLS AND METHODS IN LITERATURE AND COMPANY PRACTICE}

Tools and methods presented in traditional portfolio management literature were compared with those used in the selected agile and lean software companies, according to our four goals of portfolio management. The four goals are used as guide to report portfolio management tools and methods from the literature and software companies. Table 5 presents a synthesised outline of findings and comparison of tools and methods in traditional portfolio management literature with the portfolio management practice of agile and lean software companies.

Table 5. Comparison of portfolio management tools and methods in literature and company practice

\begin{tabular}{|l|l|l|l|}
\hline \multirow{2}{*}{$\begin{array}{l}\text { Main goal of } \\
\text { portfolio } \\
\text { management }\end{array}$} & \multicolumn{1}{|c|}{$\begin{array}{c}\text { Portfolio methods and tools } \\
\text { management literature and } \\
\text { company practice }\end{array}$} & $\begin{array}{l}\text { Only reported in } \\
\text { traditional portfolio } \\
\text { management literature }\end{array}$ & $\begin{array}{l}\text { Only reported in software company } \\
\text { practice }\end{array}$ \\
\cline { 2 - 5 } $\begin{array}{l}\text { Maximise the } \\
\text { value of the } \\
\text { portfolio }\end{array}$ & $\begin{array}{l}\text { Financial models: DCF, NPV, ROI, } \\
\text { PBP, Multi-criteria models: } \\
\text { Scoring models, Cost-Benefit } \\
\text { Analysis, market potential, technical } \\
\text { capability }\end{array}$ & $\begin{array}{l}\text { Financial models: } \\
\text { ECV, ROA, Multi- } \\
\text { criteria models: } \\
\text { Analytical Hierarchy } \\
\text { Process (AHP) }\end{array}$ & $\begin{array}{l}\text { Multi-criteria models: NPS, lean } \\
\text { metrics (Lead Time, Value } \\
\text { Throughput), product demos, product } \\
\text { experimentation }\end{array}$ \\
\hline $\begin{array}{l}\text { Ensure balance } \\
\text { among } \\
\text { portfolio } \\
\text { offerings }\end{array}$ & $\begin{array}{l}\text { Strategic buckets (key focus areas), } \\
\text { business and product roadmaps }\end{array}$ & $\begin{array}{l}\text { Portfolio matrix (such as } \\
\text { McKinsey matrix, BCG } \\
\text { matrix) }\end{array}$ & $\begin{array}{l}\text { Cumulative Flow Diagrams, Kanban, } \\
\text { Business Agilefant (items-effort } \\
\text { distribution), Burn Down Charts, ad } \\
\text { hoc process }\end{array}$ \\
\hline $\begin{array}{l}\text { Achieve } \\
\text { strategic } \\
\text { alignment of } \\
\text { the portfolio }\end{array}$ & $\begin{array}{l}\text { Strategic approaches (strategic } \\
\text { buckets, product and technology } \\
\text { roadmaps) }\end{array}$ & $\begin{array}{l}\text { Strategic alignment } \\
\text { model, Balanced } \\
\text { scorecard }\end{array}$ & $\begin{array}{l}\text { Key performance indicators (KPI), } \\
\text { Kanban, short- and long-term } \\
\text { customer relations and continuity }\end{array}$ \\
\hline $\begin{array}{l}\text { Pick the right } \\
\text { number of } \\
\text { offerings }\end{array}$ & $\begin{array}{l}\text { Capacity analysis (pipeline } \\
\text { management) }\end{array}$ & $\begin{array}{l}\text { Resource capacity } \\
\text { analysis, rank ordering } \\
\text { projects }\end{array}$ & $\begin{array}{l}\text { WIP count (Kanban principle) } \\
\text { Competency use \& performance }\end{array}$ \\
\hline
\end{tabular}

Portfolios methods (such as financial models and checklists) used by the agile and lean software companies to evaluate and maximise the value of a portfolio were similar to those described in traditional portfolio management literature. However, financial models were less preferred by companies than checklists. These checklists consisted of multiple criteria that were not formalised across all companies. Agile and lean software companies prefer to use lead time, customer preference and satisfaction, as well as other measures that solicit customer feedback. These techniques were also advocated by agile and lean methodologies. This is in contrast to portfolio management tools and methods described in the literature, particularly Cooper et al.'s [24] study, which found that the predominant portfolio tools and methods were financial methods (for example, NPV and ROI) and the least predominant were other methods such as customer appeal.

The predominant portfolio management methods used by agile and lean software companies to ensure balance among portfolio offerings were portfolio matrices. In traditional portfolio literature, portfolio matrixes (such as BCG matrix and McKinsey matrix) have been emphasised, but these were not found to be used in the studied agile and lean software companies. 
Additionally, for balancing the portfolio, the literature emphasised using parameters such as various types of initiatives or risk levels. In contrast, agile and lean software companies employed tools (such as Kanban and CFDs) that visualise the flow of items in product development activities and signal where more attention is required. Kanban is also recommended in the literature, as it helps to balance offerings in the portfolio [14]. In companies that offered R\&D services, matrices that helped to visualise the allocation of employees to customer projects according to demand and competencies were adopted. The latter was not mentioned in the portfolio management literature. Generally, portfolio mapping tools in traditional portfolio literature and in agile and lean software companies were similar, as they all emphasised the visualisation aspect through the use of graphs or charts.

In portfolio management literature, strategic buckets are the predominant method used for achieving strategic alignment of the portfolio. This is similar to what was observed in the agile and lean software companies, although different names were used to represent the method, such as key focus areas in which resources were allocated and prioritised annually according to the company's business objectives. Product and technology roadmaps were also used to ensure alignment, similar to methods proposed in the literature. Neither the literature nor the studied agile and lean companies explicitly described methods for picking the right number of offerings, other than employing different means for analysing capacity.

\section{KANBAN IN PORTFOLIO MANAGEMENT}

In light of the interviews of the experts, this section answers RQ4. The use of Kanban for portfolio management seems not to have been extensively reported in the scientific literature so far. Edmondson and McManus [22] explained that any area of research has three stages: nascent, intermediate and mature. A recent systematic literature review on Kanban [38] reported that research on Kanban in software engineering is currently nascent and requires further exploration. It is also reported that there are indications of an increasing tendency towards using Kanban in software companies.

In our earlier study [39] with lean software companies, we found out that using Kanban in software development teams resulted in various benefits, like better visibility, improved transparency of work and communication, and better control over workflow and work in progress. In some more recent books $[14,16$, 36, 40], journals (for example, Cutter IT Journal) [13] and blogs for software practitioners, it is reported that Kanban is being adopted in a wide set of circumstances, from IT operations, development and operations (DevOps), software development, and project management through to portfolio management. This is further explained by Alan Shalloway [15], who says that Kanban provides visibility and helps management make appropriate decisions about tasks based on business value.

The companies in our study had recently started to use Kanban for portfolio management, but it was still in the early stages of adoption. The companies understood the Kanban method and used it at the portfolio level. To identify high priority work and allocate resources at the portfolio level, one interviewee mentioned that Kanban 'helps in identifying and clarifying the most important (high priority) activities'. Such clarity helps management to decide what to do first, and how to adjust efforts for the organisation to stay in the market. It also helps with the management and the allocation of resources in the selection and implementation process. For example, one interviewee mentioned that 'with Kanban, it is easy to see the high priority work against available resources'. So, if a team is working on high priority tasks, the work becomes more visible at a higher level and might trigger the reassignment of resources, depending on the context. The JIRA Kanban board, one of the tools used, involves cumulative flow diagrams and aids the visualisation process. Kanban helps in finding a balance between demand and capability. As one of the interviewees observed: 'Kanban doesn't balance the portfolio, but it signals that (for example, that the working pipeline is full), and, in turn, helps us to evaluate suitable available options at a given time, and thus take the necessary actions.'

Kanban, at the portfolio level, was explained by companies B and F through the following scenario. A single business line has three Kanban tiers: (1) business-line Kanban, containing releases of all offerings; (2) program-level Kanban, containing the product features for a specific offering; and (3) team-level Kanban, containing user stories for a specific offering. The company's business goals were linked at tier (1) with business-line investments, with the help of Kanban, which made the investment visible for each business line's offerings. Similarly, at tiers (2) and (3), Kanban was used to visualise the flow of features from program-level to team-level. As a result, the workflow, along with the investment on each offering, became clearly visible at each level. JIRA was used for each Kanban tier, because it encodes and unifies tiny bits and details of the actual processes. 


\section{VALIDITY}

In this study, threats to validity were considered by following the guidelines outlined by Runeson and Höst [44]. Construct validity is concerned with obtaining the right measures for the concept being studied. A potential threat is the selection of interviewees with a view to obtaining appropriate data in order to answer the research questions. Therefore, the key informant technique was applied for selecting the pool of interviewees. Construct validity is also threatened if interview questions are misunderstood or misinterpreted. Therefore, pre-test interviews were conducted. Additionally, at the beginning of each interview session, interviewees were introduced to key concepts and terminologies used in the study in order to avoid misinterpretation.

Internal validity focuses on how to establish a causal relationship, and is mainly used for explanatory and causal studies. As this study was of an exploratory nature, internal validity was not considered.

External validity is the ability to generalise the findings to a specific context. The findings of our study give insight into the portfolio management tools and methods of seven software companies from the N4S program. The participating companies differed in terms of size and the nature of their offerings, but similar patterns were found in their portfolio management tools and methods. However, the findings should be considered with caution, because the companies in the present study cannot be assumed to represent agile and lean software companies in general.

One threat to reliability is concerned with repetition or replication that the same result would be found if study is replicated. There is always a risk that the outcome of the study is affected by the interpretation of the researcher. To mitigate this threat, the study was designed so that data was collected from different sources, existing scientific literature, and various role interviewees from seven different companies. Further, in each phase of the research process, at least two researchers were involved to reduce the risk of bias.

One limitation of this study is the fairly small number of interviewees from the participating software companies. However, we obtained rich, interesting and valuable information from the selected top level decision makers. Additionally, the responses from the key informants in the different companies were quite similar, and not much new information was added in later interviews. This means that the information was saturating sufficiently, and so no more interviewees were needed. A second limitation is the use of a single search engine (Google Scholar) in the literature review, which could lead to a risk of missing relevant studies. However, we saw that most of the portfolio management tools and methods were already identified after reading 20 out of the 200 papers. Hence, this threat is considered to be under control.

\section{DISCUSSION AND CONCLUSION}

The findings of this study revealed that agile and lean software companies used some of the traditional portfolio management tools and methods, but the emphasis was different from that described in the portfolio management literature. The main distinguishing factors were that agile and lean software companies employed tools and methods that emphasised getting immediate feedback from customers and immediate delivery of offerings to evaluate the value maximisation of the portfolio. Agile and lean companies strongly advocate frequent interaction with customers, and gaining immediate feedback on products through the quick delivery of functionality $[20,37]$. This aspect increases the probability of reducing the risk of uncertainty, and also maximises value for the customer and the company.

From the studied companies, we can identify and draw three implications of portfolio management in agile and lean software development. First, the selected agile and lean software companies actively employed tools and methods that helped facilitate customer feedback. Moreover, agile and lean approaches in software development and delivery served to lower the level of investment risk for the companies. This is because, instead of relying on financial models to evaluate value maximisation, companies relied on the immediate delivery of products to solicit customer feedback and quickly ascertain the value of products. Financial models, as portfolio management tools, require long periods of time to compute, and also to confirm their estimations after product delivery. In addition, it was found that incremental delivery and the ability to make changes at any time during product development further increased a company's ability to quickly respond to emerging opportunities.

Second, agile and lean approaches allowed companies to have more frequent and decentralised decisionmaking points, in contrast to traditional portfolio management processes, which are often plan-driven and centralised [20,37]. 
Third, the traditional literature on portfolio management methods and tools does not take into consideration customer interaction to the extent required in agile and lean software companies. Generally, these findings have important implications for traditional portfolio management processes, which tend to incorporate preplanning activities on a large scale with minimum flexibility, or which use complex methods and tools [20].

For portfolio management, a variety of methods and tools are adopted and adjusted according to the context. The findings highlight that agile and lean software companies rarely use financial models for their offerings at the portfolio level. Portfolio management tools and methods need to be dynamic and adaptable to process changes within the company. Agile, lean and Kanban adoption in companies has changed the nature of collaboration, coordination and communication in software development projects. This also illustrates a shift towards more collaborative and coordinated portfolio management processes with greater transparency, trust and frequent interaction [20].

For the studied agile and lean software companies, business strategy played a significant role and was a crucial tool for managing the portfolio. This puts emphasis on the means used to communicate the business strategy clearly across the entire company as well as its active renewal. For better portfolio management, the business strategy needs to be actively reviewed and clearly communicated across the entire company. Additionally, the software companies interviewed use Kanban at the portfolio level, which brings more visibility to the workflow and clarity with respect to high priority activities measured against resources.

This study contributes to the body of knowledge on portfolio management and agile and lean software product management by providing empirical evidence on tools and methods used to manage a portfolio of offerings. The findings highlight that agile and lean software companies have a different emphasis than that described in the traditional portfolio management literature. The main difference found was that companies relied on and employed tools and methods that solicited customer feedback and engagement. Additionally, in agile and lean software companies, Kanban played a significant role in terms of limiting the number of offerings in the portfolio and their strategic alignment. The companies that participated in this study varied in terms of size and nature of the offerings being delivered. This suggests that further studies are required to investigate portfolio management in software companies that have similar characteristics.

\section{Acknowledgments}

This research was carried out within the DIMECC (Digital, Internet, Materials \& Engineering Co-Creation) Need for Speed program, and partially funded by Tekes (the Finnish Funding Agency for Technology and Innovation), Nokia foundation grant, and Ella and Georg Ehrnrooth foundation grant. We would like to thank the participating companies.

\section{References}

1. Dolci, P., Maçada, A.: Portfolio Theory: The Contribution of Markowitz's Theory to Information System Area. Information Systems Theory. Springer New York (2012).

2. Cooper, R.G., Edgett, S.J., Kleinschmidt, E.J.: Portfolio Management for New Products. Perseus Publishing, Cambridge, Massachusetts (2001).

3. Laanti, M., Kangas, M.: Is Agile Portfolio Management Following the Principles of Large-Scale Agile? Case Study in Finnish Broadcasting Company Yle. IEEE Agile Conference. pp. 92-96. (2015).

4. Rautiainen, K., von Schantz, J., Va, J.: Supporting Scaling Agile with Portfolio Management: Case Paf.com. 44th IEEE Hawaii International Conference on System Sciences. pp. 1-10. (2011).

5. Vähäniitty, J.: Towards agile product and portfolio management, http://urn.fi/URN:ISBN:978-952-60-4506-1, (2012).

6. Roche, G.M.: Agile Portfolio Management at NYSE. IEEE Agile Conference. pp. 117-122. (2012)

7. Rodríguez, P., Markkula, J., Oivo, M., Turula, K.: Survey on agile and lean usage in Finnish software industry. In Proceedings of the ACM-IEEE International symposium on Empirical software engineering and measurement. pp. 139-148. ACM Press, New York, USA (2012).

8. Sweetman, R., Conboy, K.: Exploring the Tensions between Software Project Portfolio Management and Agile Methods: A Research in Progress Paper. 4th International Conference on Lean Enterprise Software and Systems pp. 210-217. Springer Berlin Heidelberg (2013).

9. Kalliney, M.: Transitioning from Agile Development to Enterprise Product Management Agility. IEEE Agile conference. pp. 209-213. (2009).

10. Abrantes, R., Figueiredo, J.: Feature based process framework to manage scope in dynamic NPD portfolios. International Journal of Project Management. 32, 874-884 (2014).

11. Thiry, M., Deguire, M.: Recent developments in project-based organisations. International Journal of Project Management. 25, 649-658 (2007).

12. Killen, C.P., Hunt, R.A., Kleinschmidt, E.J.: Managing the New Product Development Project Portfolio: A 
Review of the Literature and Empirical Evidence. IEEE Portland International Conference on Management of Engineering \& Technology. pp. 1864-1874. (2007).

13. Anderson, D., Roock, A.: An Agile Evolution: Why Kanban Is Catching On in Germany and Around the World. Cutter IT Journal. 24, 6-17 (2011).

14. Leffingwell, D.: Agile Software Requirements: Lean Requirements Practices for Teams, Programs, and the Enterprise. Addison-Wesley Professional, Massachusetts (2010).

15. Shalloway, A.: The Real Differences between Kanban and Scrum, http://www.netobjectives.com/blogs/realdifferences-between-kanban-and-scrum.

16. Anderson, D.: Kanban. Blue Hole Press, sequim, Washington (2010).

17. Kettunen, P., Laanti, M.: Combining agile software projects and large-scale organizational agility. Software Process: Improvement and Practice. 13, 183-193 (2008).

18. Laanti, M.: Implementing Program Model with Agile Principles in a Large Software Development Organization. 32nd Annual IEEE International Computer Software and Applications Conference. pp. 1383-1391. (2008).

19. Carbonell-Foulquié, P., Munuera-Alemán, J.L., Rodríguez-Escudero, A.I.: Criteria employed for go/no-go decisions when developing successful highly innovative products. Industrial Marketing Management. 33, $307-$ 316 (2004).

20. Stettina, C.J., Hörz, J.: Agile portfolio management: An empirical perspective on the practice in use. International Journal of Project Management. 33, 140-152 (2015).

21. Maylor, H.: Project Management. Prentice Hall, New Jersey, USA (2010).

22. Edmondson, A.C., McManus, S.E.: Methodological Fit in Management Field Research. Academy of Management Review. 32, (2007).

23. Linenberg, Y., Stadlker, Z., Arbuthnot, S.: Optimising organisational performance by managing project benefits, Europe (2003).

24. Cooper, R., Edgett, S., Kleinschmidt, E.: Portfolio management for new product development: results of an industry practices study. R\&D Management. 31, 361-380 (2001).

25. Blomquist, T., Müller, R.: Practices, Roles and Responsibilities of Middle Managers in Program and Portfolio Management. Project Management Journal. 37, 52-66 (2006).

26. Frey, T., Buxmann, P.: IT Project Portfolio Management - A Structured Literature Review. European Conference on Information Systems. p. Paper 167 (2012).

27. Cooper, R., Edgett, S., Kleinschmidt, E.: Portfolio management for new product development: results of an industry practices study. $R \& D$ Management. 31, 361-380 (2001).

28. Cooper, Robert; Edgett, Scott; Kleinschmidt, E.: Portfolio Management: Fundamental to New Product Success. In: Belliveau, Paul; Griffin, Abbie; Somermeyer, S. (ed.) The PDMA ToolBook 1 for New Product Development. pp. 331-364. John Wiley \& Sons, New York (2002).

29. Mikkola, J.H.: Portfolio management of R\&D projects: implications for innovation management. Technovation. 21, 423-435 (2001).

30. van de Weerd, I., Brinkkemper, S., Nieuwenhuis, R., Versendaal, J., Bijlsma, L.: Towards a Reference Framework for Software Product Management.14th International Requirements Engineering Conference. pp. 319-322 (2006).

31. Maglyas, A., Nikula, U., Smolander, K.: What do we know about software product management? - a systematic mapping study. 5th IEEE International Workshop on Software Product Management. pp. 26-35. (2011).

32. Reyck, B. De, Grushka-Cockayne, Y., Lockett, M., Calderini, S.R., Moura, M., Sloper, A.: The impact of project portfolio management on information technology projects. International Journal of Project Management. 23, 524-537 (2005).

33. Cooper, R.G., Edgett, S.J., Kleinschmidt, E.J.: New Problems, New Solutions: Making Portfolio Management More Effective. Research-Technology Management. 43, 18-33 (2000).

34. PMI: The standard for portfolio management, (2008).

35. Hodgkins, P., Hohmann, L.: Agile Program Management: Lessons Learned from the VeriSign Managed Security Services Team. IEEE Agile conference. pp. 194-199. (2007).

36. Krebs, J.: Agile Portfolio management. Microsoft Press, Washington (2009).

37. Bhattacharya, S., Krishnan, V., Mahajan, V.: Managing New Product Definition in Highly Dynamic Environments. Management Science. 44, 50-64 (1998).

38. Ahmad, M.O., Markkula, J., Oivo, M.: Kanban in software development: A systematic literature review. IEEE 39th Euromicro Conference on Software Engineering and Advanced Applications. pp. 9-16. (2013).

39. Ahmad, M.O., Markkula, J., Oivo, M., Kuvaja, P.: Usage of Kanban in Software Companies An empirical study on motivation, benefits and challenges. 9th International Conference on Software Engineering Advances (2014).

40. Burrows, M.: Kanban from the Inside: Understand the Kanban Method, connect it to what you already know, introduce it with impact. Blue Hole Press, Sequim, Washington (2014).

41. Wohlin, C.: Guidelines for snowballing in systematic literature studies and a replication in software engineering. Proceedings of the 18th International Conference on Evaluation and Assessment in Software Engineering. pp. 110. ACM Press, New York, New York, USA (2014).

42. Webster, J., Watson, R.: Analyzing the past to prepare for the future: Writing a literature review. Management Information Systems Quarterly. 26, 13-19 (2002).

43. Jalali, S., Wohlin, C.: Systematic literature studies. Proceedings of the ACM-IEEE international symposium on Empirical software engineering and measurement. p. 29. ACM Press, New York, USA (2012).

44. Runeson, P., Höst, M.: Guidelines for conducting and reporting case study research in software engineering. Empirical software engineering. (2009).

45. Kumar, N., Stern, L.W., Anderson, J.C.: Conducting interorganizational research using key informants. Academy of Management Journal. 36, 1633-1651 (1993).

46. King, N.: Template analysis. In: Symon, Gillian; Cassell, C. (ed.) Qualitative methods and analysis in organizational research: A practical guide. pp. 118-134. Sage Publications Ltd, Thousand Oaks, CA (1998).

47. Ahmad, M. O., Kuvaja, P., Oivo, M., \& Markkula, J.: Transition of software maintenance teams from Scrum to 
Kanban. IEEE proceedings of 49th Hawaii International Conference on System Sciences. pp. 5427-5436. (2016). Ahmad, M. O., Markkula, J., \& Oivo, M.: Insights into the Perceived Benefits of Kanban in Software Companies: Practitioners' Views. International Conference on Agile Software Development.pp. 156-168. Springer International Publishing. (2016).

\section{Appendix A.}

[S1] Barczak, Gloria, Abbie Griffin, and Kenneth B. Kahn. Perspective: trends and drivers of success in NPD practices: results of the 2003 PDMA best practices study. Journal of product innovation management, 2009, 26(1): 3-23.

[S2] Chao, Raul O., and Stylianos Kavadias. A theoretical framework for managing the new product development portfolio: when and how to use strategic buckets. Management Science, 2008, 54(5): 907-921.

[S3] Cooper, Robert, Scott Edgett, and Elko Kleinschmidt. Portfolio management for new product development: results of an industry practices study. $R \& D$ Management, 2001, 31(4): 361-380.

[S4] Cooper, Robert G., Scott J. Edgett, and Elko J. Kleinschmidt. New problems, new solutions: making portfolio management more effective. Research-Technology Management, 2000, 43(2): 18-33.

[S5] Cooper, Robert G., and Scott J. Edgett. Maximizing productivity in product innovation. Research- Technology Management, 2008, 51(2): 47-58.

[S6] Cooper, Robert G., and Scott J. Edgett. Overcoming the crunch in resources for new product development. Research-Technology Management, 2003, 46(3): 48-58.

[S7] Cooper, Robert G., Scott J. Edgett, and Elko J. Kleinschmidt. Benchmarking best NPD practices-II: strategy, resource allocation and portfolio management Are the Focus of This Second in a Three-Part Series. ResearchTechnology Management, 2004, 47(3): 50.

[S8] Dickinson, Michael W., Anna C. Thornton, and Stephen Graves. Technology portfolio management: optimizing interdependent projects over multiple time periods. IEEE Transactions on Engineering Management, 2001, 48(4): 518-527.

[S9] Augusto Cauchick Miguel, Paulo. Portfolio management and new product development implementation: A case study in a manufacturing firm. International Journal of Quality \& Reliability Management, 2008, 25(1): 10-23.

[S10] Killen, Catherine P., Robert A. Hunt, and Elko J. Kleinschmidt. Project portfolio management for product innovation. International Journal of Quality \& Reliability Management, 2008, 25(1): 24-38.

[S11] Killen, Catherine P., Robert A. Hunt, and Elko J. Kleinschmidt. Managing the new product development project portfolio: a review of the literature and empirical evidence. In International Center for Management of Engineering and Technology Portland proceedings, IEEE, 2007, 1864-1874.

[S12] Kohlborn, Thomas, Erwin Fielt, Axel Korthaus, and Michael Rosemann. Towards a service portfolio management framework. In Evolving Boundaries and New Frontiers: Defining the IS Discipline: Proceedings of the 20th Australasian Conference on Information Systems, 2009, 861-870.

[S13] Meskendahl, Sascha. The influence of business strategy on project portfolio management and its Success-a conceptual framework.International Journal of Project Management, 2010, 28(8):807-817

[S14] Mikkola, Juliana Hsuan. Portfolio management of R\&D projects: implications for innovation management. Technovation, 2001, 21(7): 423-435.

[S15] Oliveira, Maicon G., and Henrique Rozenfeld. Integrating technology roadmapping and portfolio management at the front-end of new product development. Technological forecasting and social change, 2010, 77(8): 1339-1354.

[S16] Adams, Richard, John Bessant, and Robert Phelps. Innovation management measurement: A review. International Journal of Management Reviews, 2006, 8(1): 21-47.

[S17] Christiansen, John K., and Claus Varnes. From models to practice: decision making at portfolio meetings. International Journal of Quality \& Reliability Management, 2008, 25(1): 87-101.

[S18] Lee, Hakyeon, Chulhyun Kim, and Yongtae Park. Evaluation and management of new service concepts: An ANPbased portfolio approach. Computers \& Industrial Engineering, 2010, 58(4): 535-543.

[S19] Lin, Chinho, and Ping-Jung Hsieh. A fuzzy decision support system for strategic portfolio management. Decision Support Systems, 2004, 38(3): 383-398.

[E1] Loch, Christoph H., and Stylianos Kavadias. Dynamic portfolio selection of NPD programs using marginal returns. Management Science, 2002, 48(10): 1227-1241.

[E2] Gustafsson, Janne, and Ahti Salo. Contingent portfolio programming for the management of risky projects. Operations research, 2005, 53(6): 946-956.

[E3] Hart, Susan, Erik Jan Hultink, Nikolaos Tzokas, and Harry R. Commandeur. Industrial companies' evaluation criteria in new product development gates. Journal of Product Innovation Management, 2003, 20(1): 22-36.

[E4] Lee, Sungjoo, Sungryong Kang, Euisuk Park, and Yongtae Park. Applying technology road-maps in project selection and planning. International Journal of Quality \& Reliability Management, 2008, 25(1): 39-51.

[E5] Bordley, Robert. Determining the appropriate depth and breadth of a firm's product portfolio. Journal of Marketing Research, 2003, 40(1): 39-53. 